\title{
Vibro-acoustic performance of steel-concrete composite and prestressed concrete box girders subjected to train excitations
}

\author{
Xun Zhang ${ }^{1,2}$ (1) Hao Luo ${ }^{1} \cdot$ Derui Kong $^{1} \cdot$ Tao Chen $^{1} \cdot \mathrm{Xi} \mathrm{Li}^{1}$
}

Received: 19 February 2021/Revised: 16 July 2021 / Accepted: 17 July 2021 / Published online: 22 August 2021

(C) The Author(s) 2021

\begin{abstract}
Owning to good mechanical properties, steelconcrete composite (SCC) and prestressed concrete (PC) box girders are the types of elevated structures used most in urban rail transit. However, their vibro-acoustic differences are yet to be explored in depth, while structure-radiated noise is becoming a main concern in noise-sensitive environments. In this work, numerical simulation is used to investigate the vibration and noise characteristics of both types of box girders induced by running trains, and the numerical procedure is verified with data measured from a PC box girder. The mechanism of vibration transmission and vibro-acoustic comparisons between SCC and PC box girders are investigated in detail, revealing that more vibration and noise arise from SCC box girders. The vibration differences between them are around 7.7 $\mathrm{dB}(\mathrm{A})$ at the bottom plate, $19.3 \mathrm{~dB}(\mathrm{~A})$ at the web, and $6.7 \mathrm{~dB}(\mathrm{~A})$ at the flange, while for structure-radiated noise, the difference is around $5.9 \mathrm{~dB}(\mathrm{~A})$. Then, potential vibroacoustic control strategies for SCC box girders are discussed. As the vibro-acoustic responses of two types of girders are dominated by the force transmitted to the bridge deck, track isolation is better than structural enhancement. It is shown that using a floating track slab can make the vibration and noise of an SCC box girder lower than those of a PC box girder. However, structural enhancement for the SCC box girder is extremely limited in effects. The six proposed structural enhancement measures reduce
\end{abstract}

Xun Zhang

zhxunxun@swjtu.edu.cn

1 School of Civil Engineering, Southwest Jiaotong University, Chengdu 610031, China

2 MOE Key Laboratory of High-Speed Railway Engineering, Southwest Jiaotong University, Chengdu 610031, China vibration by only $1.1-3.6 \mathrm{~dB}(\mathrm{~A})$ and noise by up to $1.5 \mathrm{~dB}(\mathrm{~A})$.

Keywords Urban rail transit - Vibration - Noise · Box girder · Vibro-acoustic control

\section{Introduction}

With the rapid development of urban rail transit, residents are increasingly complaining about the vibration and noise induced by running trains. Steel-concrete composite (SCC) and prestressed concrete (PC) box girders (BGs) are commonly used in urban rail transit (see Fig. 1), with the latter used in the vast majority of elevated bridges [1]. Compared to the case of a train running on a normal track at ground level, more noise arises when a train crosses a bridge, which is typically $10 \mathrm{~dB}$ or more, with all-steel or SCC bridges generally producing more noise than concrete ones [2-4]. Hence, the present study aims to investigate the vibro-acoustic differences between SCC and PC BGs and to seek potential control measures for the former.

In the past several decades, there have been many numerical and experimental investigations of the bridge vibration and vibration-induced noise. For the vibroacoustic response of concrete bridges, a hybrid two-stage predictive method is usually used, with the first stage usually computing the vibration based on the coupled train-track-bridge vibration theory combined with the finite element method (FEM). The key point of this stage is that shell and/or solid elements are required in FE analysis to obtain the local vibrations of bridge components [5-7]. 

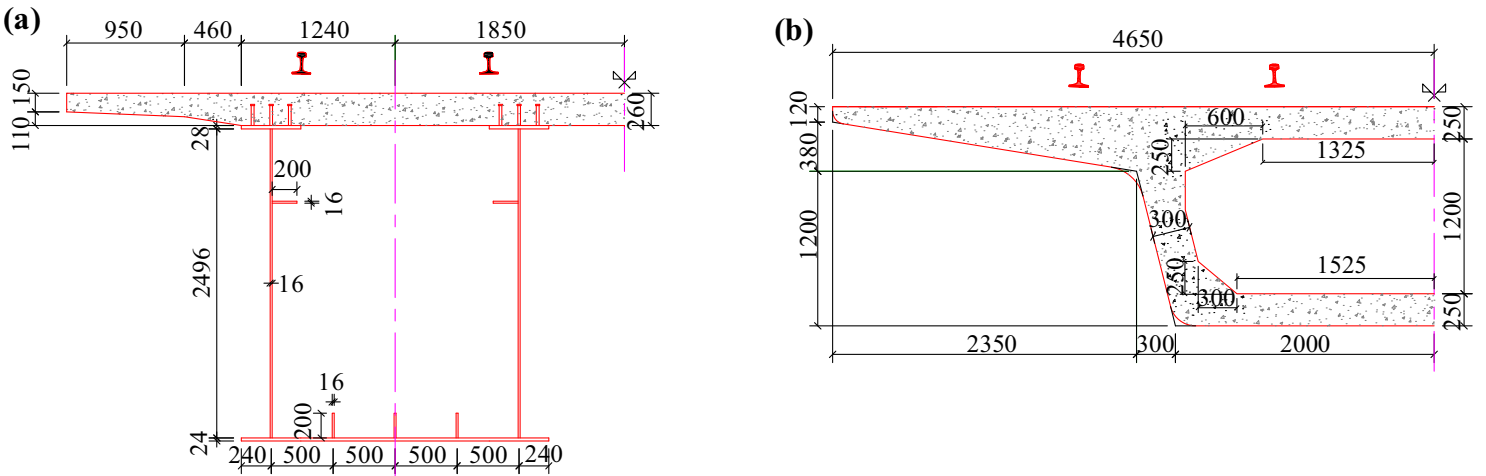

Fig. 1 Dimensions of cross sections (in $\mathrm{mm}$ ): a steel-concrete composite and $\mathbf{b}$ prestressed concrete box girders

The second stage is to calculate the noise radiation via the boundary element method (BEM). Ngai and $\mathrm{Ng}$ [8] used the FEM to validate resonance frequencies for noise and vibration. Li et al. $[9,10]$ calculated the vibration and noise of a concrete BG by using a hybrid FE-BEM and validated the results with in situ measurements. Both studies concluded that vibration resonance is more significant than acoustic resonance. Consequently, Zhang et al. [11] analyzed some efficient noise-control means by optimizing the structural parameters, i.e., increasing the thickness of the deck plate, adjusting the inclination angle of the web, and adding a longitudinal clapboard. Li et al. [6] used the FEM to obtain the vibration of a U-shaped PC girder and then found the frequency-dependent modal acoustic transfer vectors by boundary element method (BEM) to derive the structure-borne noise.

However, the aforementioned FE-BEM methods are generally quite time consuming. For improved computational efficiency, Li et al. [12] and Song et al. [13, 14] used a three-dimensional dynamic model to obtain the vibration of a concrete bridge and 2.5-dimensional BEM or the twodimensional infinite element method to predict structureborne noise. Recently, Li and Thompson [15] proposed a wavenumber-domain FE and BEM to predict rail and bridge vibro-acoustic responses. Song et al. [16] used a hybrid waveguide FE and two-dimensional BEM to analyze a concrete continuous rigid-frame BG bridge. Song et al. [17] used the same method to investigate the mediumand high-frequency vibration characteristics of a BG. However, although the waveguide FEM reduces the computation time greatly, it is suitable only for structures with constant cross section in the longitudinal direction. The idea of this method was applied to calculating vibration and sound radiation of a train wheel, which considers wheel rotation but only requires a $2 \mathrm{D}$ mesh over a cross section containing the wheel axis [18].

Because the structure-borne noise from an SCC or allsteel bridge can have frequencies up to $1 \mathrm{kHz}$ and these structures usually have many vibration modes in this frequency range, vibro-acoustic prediction using FEM and BEM would be extremely costly in computation. This is why previous studies were focused mainly on low frequencies or a small bridge section. For example, Augusztinovicz et al. [19] regarded the track isolation as a 1D mass-spring system to obtain the excitation and then used FEM and BEM to calculate the noise radiated from a steel BG bridge below $200 \mathrm{~Hz}$. Alten and Flesch [4] used FEM to investigate measures for reducing the noise from a steel-truss bridge and found the critical contribution to be that radiated from the web of the main girder.

Because statistical energy analysis (SEA) is very efficient for predicting the high-frequency vibrations of large structures, it is used widely to calculate the vibro-acoustic responses of SCC or all-steel bridges. Li et al. [20] and Liu et al. [21] proposed hybrid an FE-SEA to discuss the vibration and noise characteristics of an SCC bridge that comprised two I-shaped steel girders and a concrete deck, and that method was also applied to a long-span steel-truss cable-stayed bridge [22]. To lower the computational cost further, Liu et al. [23] established a coupled wheel-track model to obtain the excitation transmitted to the bridge and then used FEM for the concrete deck and SEA to model the steel girders. They found that SCC bridge-borne noise increases with train speed $v$ by approximately $20 \log (v)$. However, note that some SEA parameters are difficult to determine and sufficient experimental data are needed [20, 24, 25]. By contrast, the FEM is preferable for exploring the vibration transmission mechanism, especially for complicated structures. For example, Zhang et al. [26] built a detailed coupled train-track model to analyze the dynamic characteristics of the track structure and developed a predictive FEM-based model for the bridge-borne noise from a long-span steel-truss cable-stayed bridge.

In the present study, the vibro-acoustic responses of SCC and PC BGs are compared via numerical simulations. First, an elaborate coupled train-track model is established 
in the frequency domain to derive the forces transmitted to the bridge deck; then the FEM is used to obtain the vibration responses and distribution rules. The noise radiated from the vibrating BG plates is considered to be the total noise radiated from infinitesimal semispherical oscillators that are formed by dividing the BG plates into infinitesimal areas (i.e., FE meshes). The approach is validated by comparing the numerical results with in situ measurement data from a PC BG. Finally, some strategies for controlling the vibration and noise of an SCC BG are discussed, including track isolation and structural enhancement.

\section{Predictive method}

Figure 2 shows the numerical procedure for simulating the radiated noise from an SCC or PC BG induced by train excitations. The vibro-acoustic response is calculated in three steps: (i) train-track interaction model-determining analytically the dynamic forces transmitted to the bridge deck, (ii) calculation of bridge vibration-conducting a standard harmonic analysis using general FE software, and (iii) calculation of noise radiation-integrating the noise from infinitesimal semispherical oscillators. This numerical simulation procedure is not entirely new, and some derivations can be found in our previous publications [26, 27]. Herein, we outline briefly the method and its underlying logic.

\subsection{Train-track interaction analysis}

The train-track interaction model is restricted to the vertical direction because the noise radiated from a bridge due to lateral train excitation can be neglected [2]. A solution strategy is formulated in the frequency domain to reduce the computational expense. The lower frequency limit of audible sound is $20 \mathrm{~Hz}$ and bridge-radiated noise occurs mainly below about $1 \mathrm{kHz}$; hence the frequency range considered herein is $20-1000 \mathrm{~Hz}$. We show later in Sect. 3.2 that the receptance (displacement divided by force) of the bridge deck for both SCC and PC BGs in the

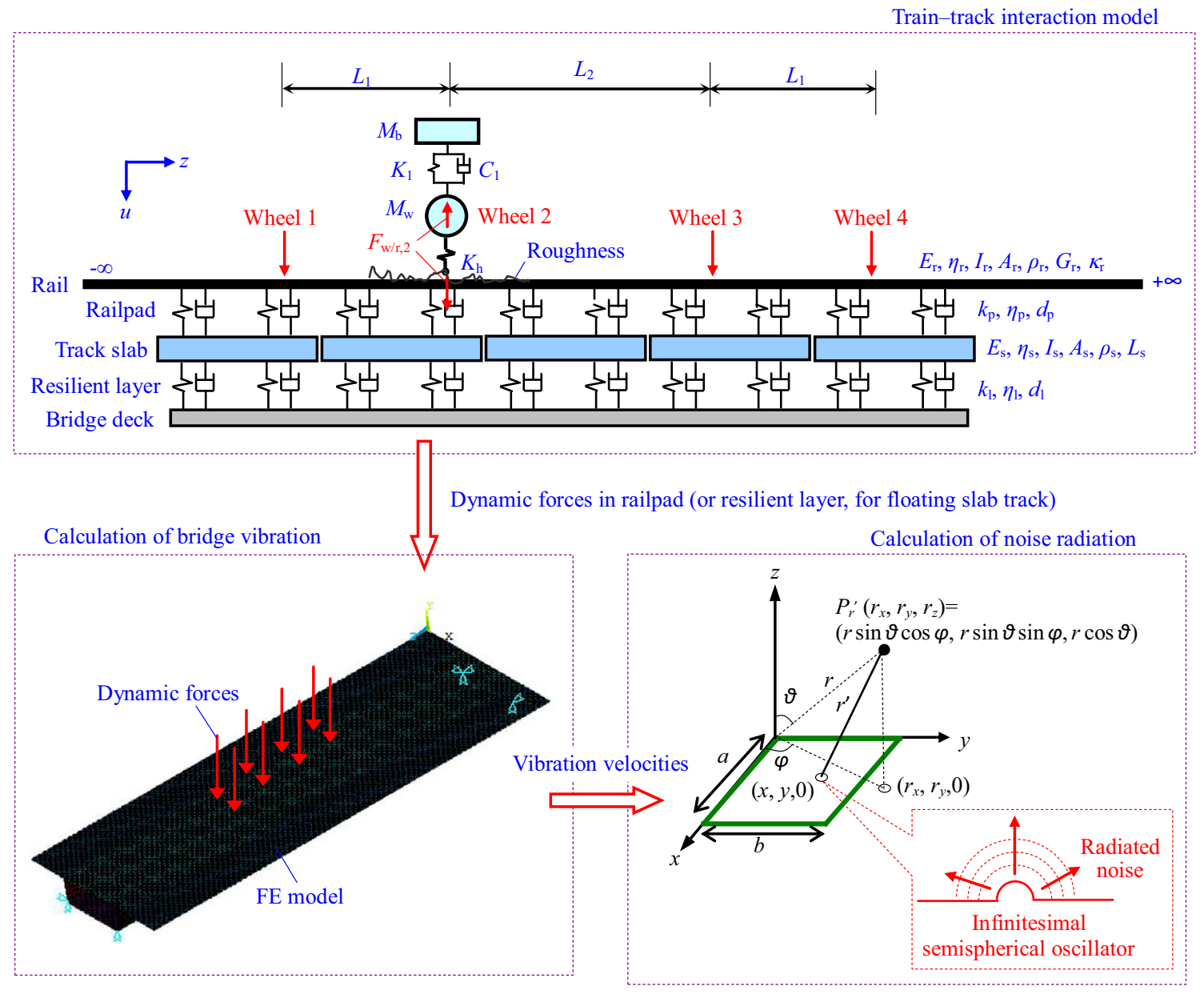

Fig. 2 Schematic of numerical simulation procedure 

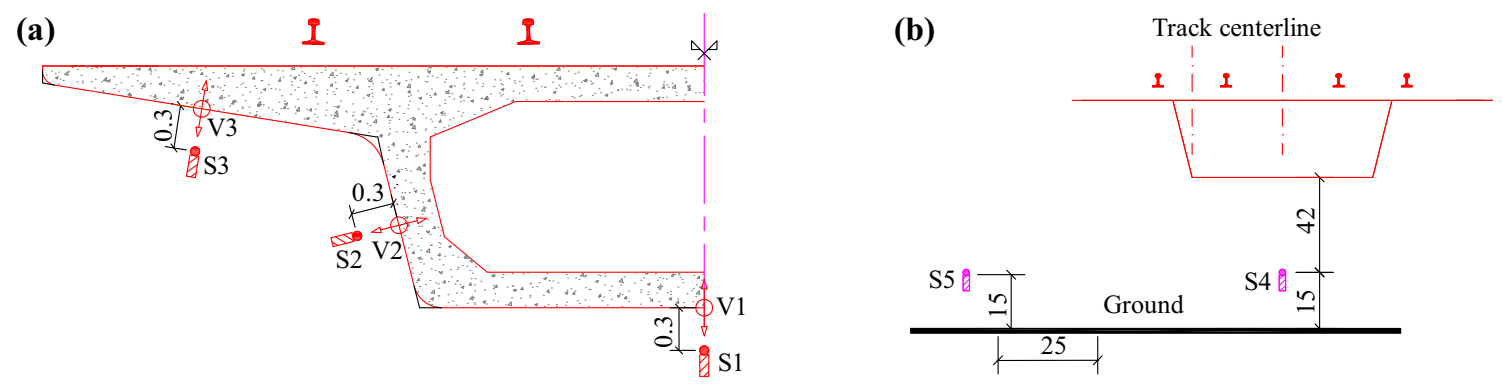

Fig. 3 Arrangement of measuring points (in mm): a vibration (V1-V3) and near-field noise (S1-S3); b noise underneath girder (S4) and wayside noise (S5)

range of $20-1000 \mathrm{~Hz}$ is much smaller than that of the track; thus it is reasonable to treat the bridge deck as a rigid body $[23,26]$. In this context, the track-bridge system can be calculated separately without reducing accuracy.

We introduce a $1 / 8$ vehicle model, including an unsprung mass $\left(M_{\mathrm{w}}\right)$ to represent the wheel, and a $1 / 4$ bogie model to represent the primary suspension (stiffness $K_{1}$, damping $\left.C_{1}\right)$ and mass of the bogie $\left(M_{\mathrm{b}}\right)$. The wheel-rail system is excited by the roughness of the rail surface. In the simple case of a single wheel, the vertical contact force $F$ is given as [2, 28]

$F=-\left(\alpha_{\mathrm{w}}+1 / K_{\mathrm{h}}+\alpha_{\mathrm{t}}\right)^{-1} \Delta$,

where $\Delta$ is the track roughness spectrum; $\alpha_{\mathrm{w}}$ and $\alpha_{\mathrm{t}}$ are the wheel and track receptances, respectively, at the contact point; and $K_{\mathrm{h}}$ is the stiffness of the linearized contact spring between the wheel and the rail.

The concept of "active" and "passive" wheels was introduced to study the effects of multiple wheel-rail interactions [29], leading to cross-interactions among multiple wheels due to wave propagation along the rail. The wheel-rail contact force at a certain wheel position (e.g., $F_{\mathrm{w} / \mathrm{r}, 2}$ at wheel 2, as shown in Fig. 2) is a combination of (i) the active force caused by the local roughness and (ii) the passive force induced from rail vibrations that originate at the other wheels. The four wheels shown in Fig. 2 correspond to the adjacent bogies between the forward and backward vehicles. The wheelbase and distance of adjacent wheels between neighboring vehicles are denoted by $L_{1}$ and $L_{2}$, respectively. These four wheels are proven to be adequate for considering the effects of multiple wheel-rail interactions [27, 29].

The track is modeled as a multi-layer beam-spring system laid on a bridge deck. The rail is modeled with an infinite Timoshenko beam. The track slab is modeled using a free-free Euler-Bernoulli beam. The railpad and the resilient layer underneath the track slab are modeled as damped springs. This track model can be used to calculate the forces transmitted to a bridge deck paved with either a normal or a floating slab track. For a normal slab track, the
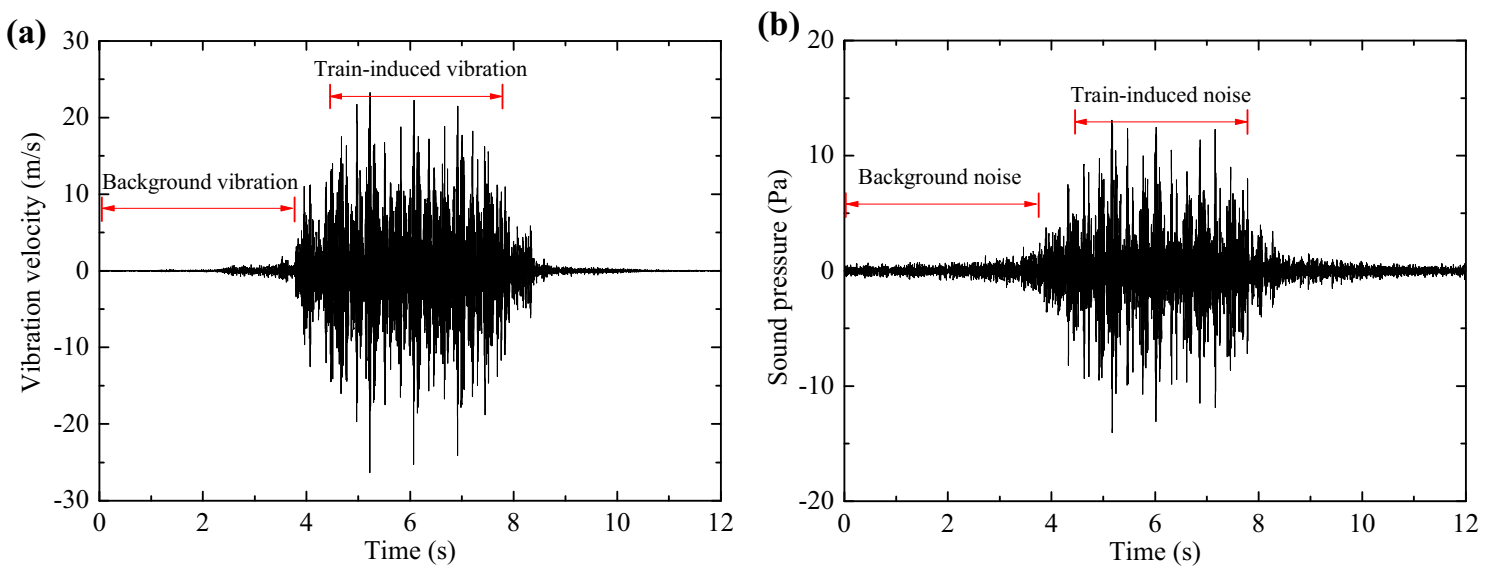

Fig. 4 Typical recordings in time domain: a vibration velocity and $\mathbf{b}$ sound pressure 

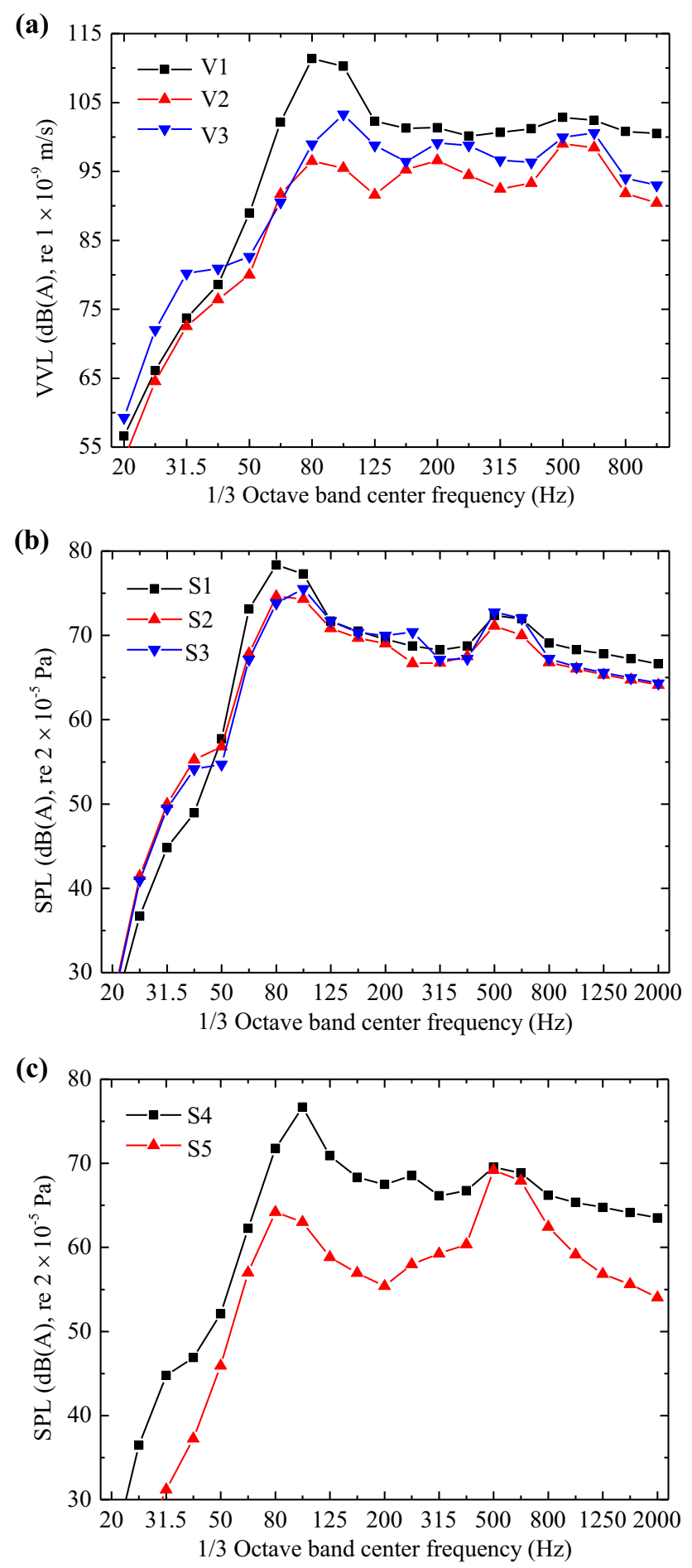

Fig. 5 Spectral analysis of measured results: a bridge vibration, b near-field noise, and $\mathbf{c}$ far-field noise

stiffness of the resilient layer underneath the track slab is set as a large value $\left(10^{4} \mathrm{MN} / \mathrm{m}\right.$ or so), while for a floating slab track the actual stiffness is set. The dynamic equations of the train-track interaction model are illustrated in Ref. [26].

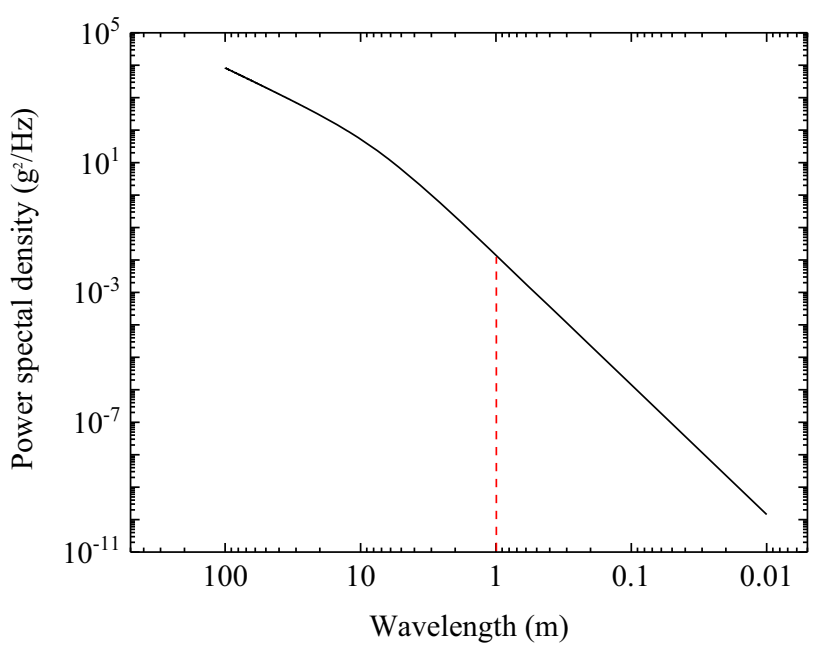

Fig. 6 Power spectra density of vertical track roughness

The forces transmitted to the bridge deck are considered as being applied at certain constant locations, as shown in Fig. 2. In frequency response analysis, when calculating bridge vibrations, it is a common practice to apply the excitation forces at representative locations along the bridge girder, e.g., end, 1/8, 1/4, 3/8, and mid-span. The wheel/rail forces are at various longitudinal positions of the bridge girder to determine the mean-square responses at a specific location in both the time and frequency domains.

\subsection{Vibro-acoustic modeling}

For BGs, all plate members including the deck, flange, web, and bottom plate contribute to the structure-borne noise. As previously mentioned, the plate members are divided into infinitesimal areas that are treated as infinitesimal semispherical oscillators, and the noise radiated from a vibrating BG is considered to be the sum of noise from these oscillators, as shown in Fig. 2 [30]. Because these plate members are meshed with four-node plate/shell elements in the FE analysis, these elements are regarded as the oscillators. The sound pressures radiated from these infinitesimal oscillators are then integrated over the vibrating plate as follows:

$P_{r^{\prime}}=\iint \frac{j \rho_{a} c_{a} k_{a}}{2 \pi r^{\prime}} v_{s} e^{-j k_{a} r^{\prime}} d S$,

where $\rho_{\mathrm{a}}$ is the air density, $c_{\mathrm{a}}$ is the sound velocity in air, $k_{\mathrm{a}}$ is the wavenumber, $v_{\mathrm{s}}$ is the vibration velocity of oscillator, $r^{\prime}$ is the distance between the center of the oscillator and the noise investigation point, and $\mathrm{j}$ is the imaginary unit.

Once the sound pressure is obtained from Eq. (2). The sound pressure level (SPL) can be calculated. The sound pressure is closely related to the vibration velocity, and so the vibration velocity level (VVL) is discussed herein in 
Table 1 Train and track parameters

\begin{tabular}{|c|c|c|c|c|c|}
\hline Object & Item & Value & Object & Item & Value \\
\hline \multirow[t]{8}{*}{ Train } & $1 / 4$ bogie mass $M_{\mathrm{b}}(\mathrm{t})$ & 0.7125 & Railpad & Normal stiffness $k_{\mathrm{p}}(\mathrm{MN} / \mathrm{m})$ & 60 \\
\hline & $1 / 2$ wheelset mass $M_{\mathrm{w}}(\mathrm{t})$ & 0.575 & & Low stiffness $k_{\mathrm{p}}(\mathrm{MN} / \mathrm{m})$ & 6 \\
\hline & Stiffness of primary suspension $K_{1}(\mathrm{MN} / \mathrm{m})$ & 1.0 & & Spacing $d_{\mathrm{p}}(\mathrm{m})$ & 0.625 \\
\hline & Damping of primary suspension $C_{1}(\mathrm{kN} \cdot \mathrm{s} / \mathrm{m})$ & 50 & & Damping loss factor $\eta_{\mathrm{p}}$ & 0.25 \\
\hline & Contact stiffness $K_{\mathrm{h}}(\mathrm{MN} / \mathrm{mm})$ & 1.4 & Track slab & Cross-sectional area $A_{\mathrm{s}}\left(\mathrm{m}^{2}\right)$ & 0.98 \\
\hline & Speed $(\mathrm{km} / \mathrm{h})$ & 70 & & Area moment $I_{\mathrm{s}}\left(\mathrm{m}^{4}\right)$ & $1.0 \times 10^{-2}$ \\
\hline & Wheelbase $L_{1}(\mathrm{~m})$ & 2.0 & & Length $L_{\mathrm{s}}(\mathrm{m})$ & 5 \\
\hline & $\begin{array}{l}\text { Distance of adjacent wheels between } \\
\text { neighboring vehicles } L_{2}(\mathrm{~m})\end{array}$ & 3.3 & & Young's modulus $E_{\mathrm{s}}\left(\mathrm{N} / \mathrm{m}^{2}\right)$ & $3.5 \times 10^{10}$ \\
\hline \multirow[t]{5}{*}{ Rail } & Mass per meter $A_{\mathrm{r}} \rho_{\mathrm{r}}(\mathrm{kg} / \mathrm{m})$ & 60 & & Density $\rho_{\mathrm{s}}\left(\mathrm{kg} / \mathrm{m}^{3}\right)$ & $2.5 \times 10^{3}$ \\
\hline & Bending stiffness $E_{\mathrm{r}} I_{\mathrm{r}}\left(\mathrm{MN} \cdot \mathrm{m}^{2}\right)$ & 6.63 & & Damping loss factor $\eta_{\mathrm{s}}$ & 0.05 \\
\hline & Shear coefficient $G_{\mathrm{r}}\left(\mathrm{N} / \mathrm{m}^{2}\right)$ & $7.7 \times 10^{10}$ & Resilient layer & Stiffness $k_{1}(\mathrm{MN} / \mathrm{m})$ & 8.5 \\
\hline & Shear modulus $\kappa_{\mathrm{r}}$ & 0.4 & & Spacing $d_{1}(\mathrm{~m})$ & 1.25 \\
\hline & Damping loss factor $\eta_{\mathrm{r}}$ & 0.01 & & Damping loss factor $\eta_{1}$ & 0.25 \\
\hline
\end{tabular}

(a)

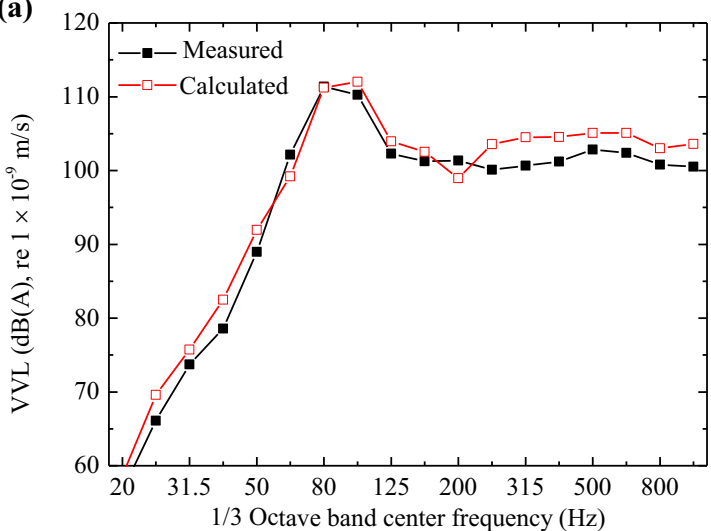

(c)

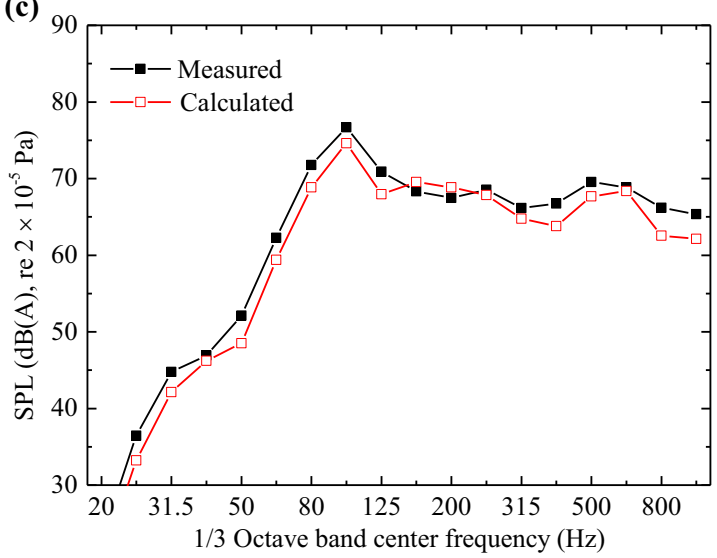

(b)

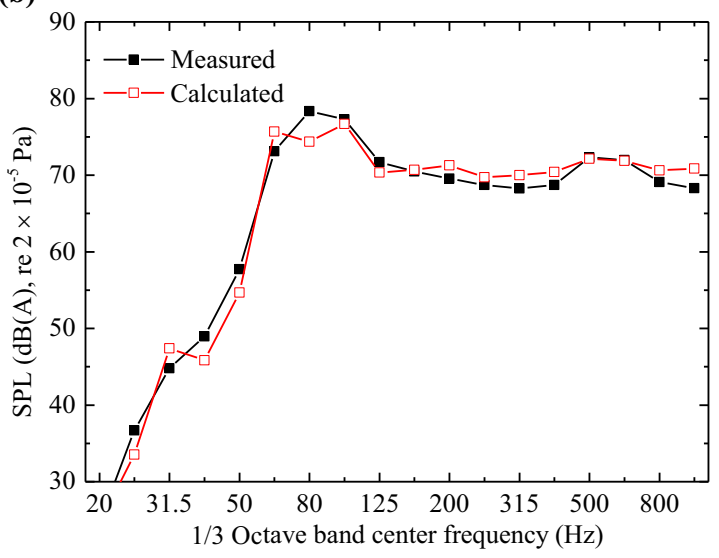

(d)

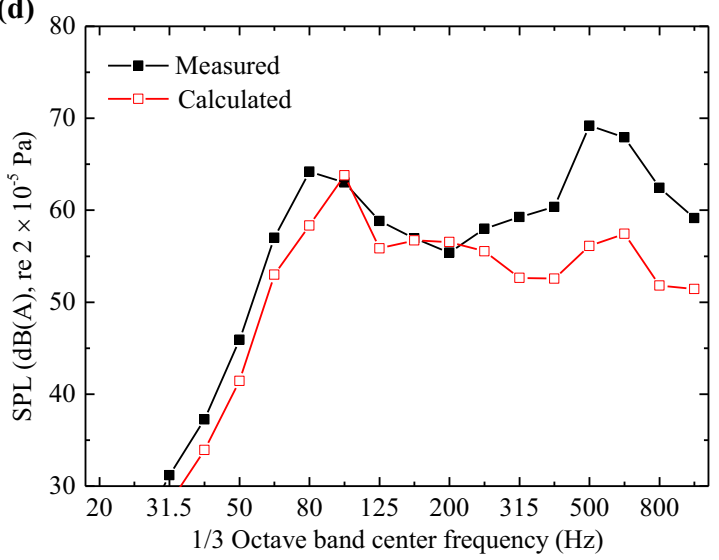

Fig. 7 Comparison of measured and calculated results: a V1, b S1, c S4, and d S5

relation to the SPL. At a point close to a specific plate member, the sound pressure depends entirely on the corresponding plate member; by contrast, at a distant point, all members of the BG contribute to the overall SPL and the directional characteristic of the sound is neglected. In addition, the shielding effect of panels on noise transmission is not considered. Note that stiffeners welded on the inner sides of plate members are not considered in the 


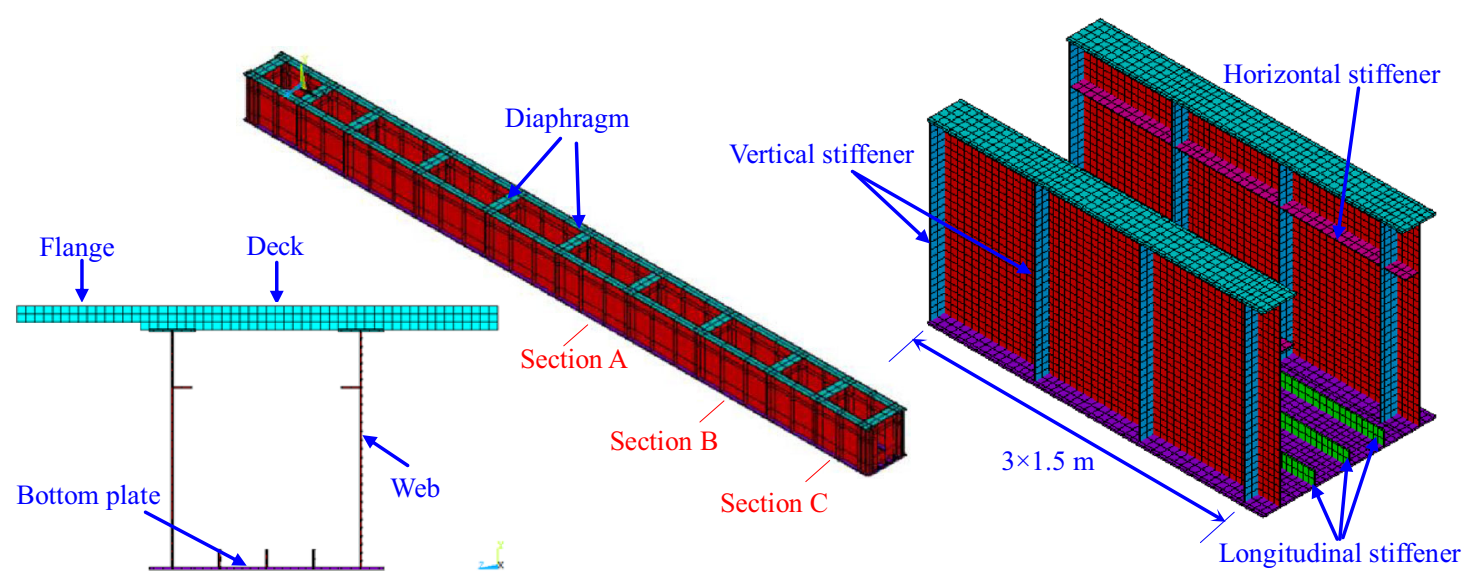

Fig. 8 Finite element model of SCC BG
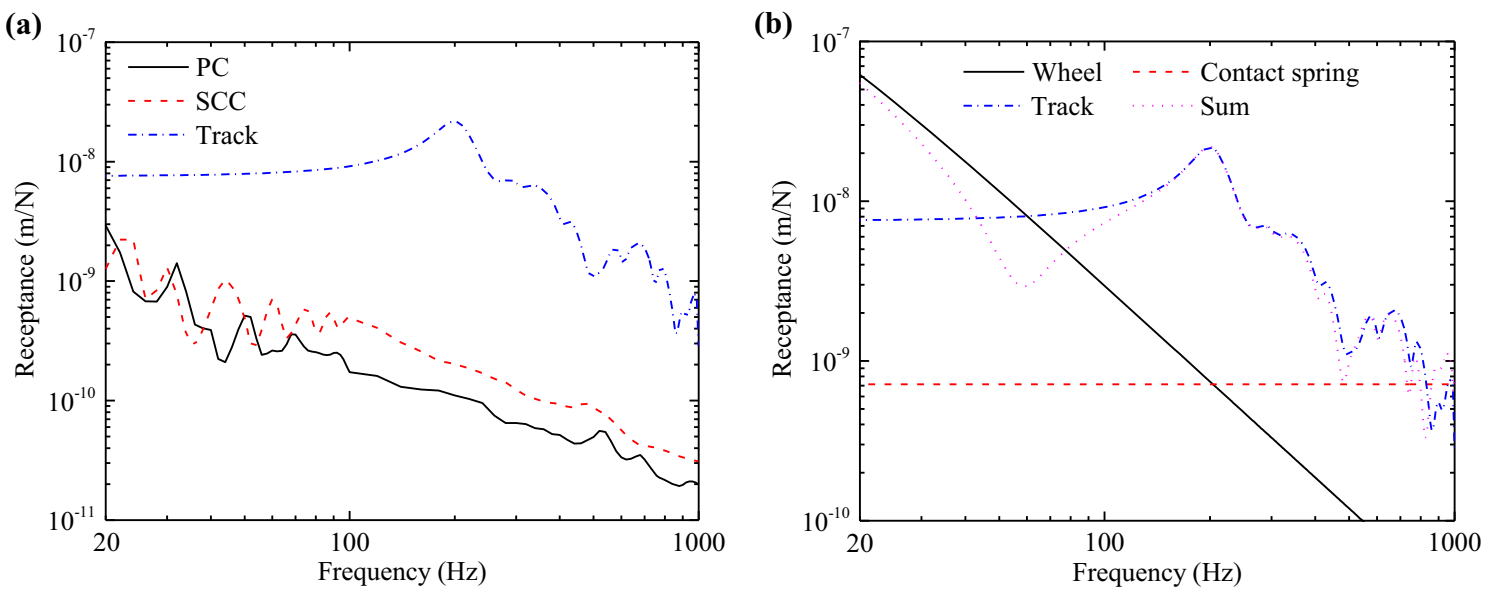

Fig. 9 Calculated receptances: a track (with assumption of rigid bridge deck) and BG (without consideration of track); b wheel, contact spring, track, and their sum
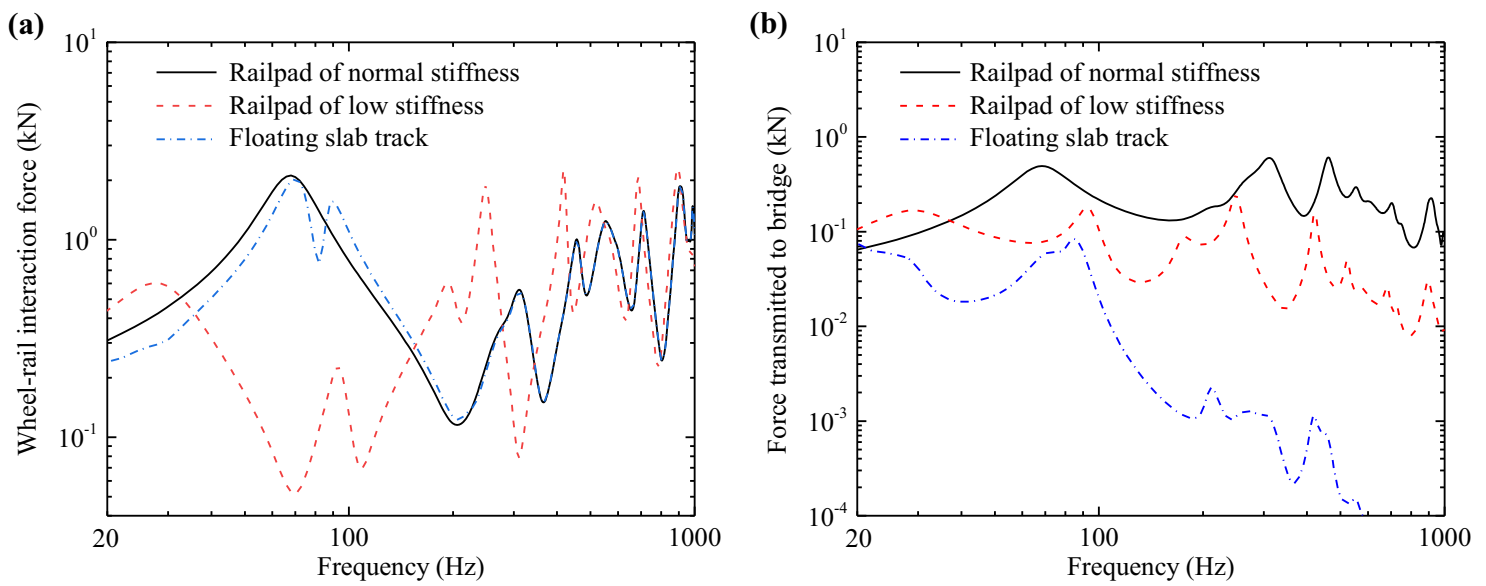

Fig. 10 Calculated forces: a wheel-rail interaction force and $\mathbf{b}$ force transmitted to bridge 
sound pressure superposition, but their stiffening effects are considered in the vibration analysis and will be discussed for possible noise control. Because the radiation ratios for different plate members are not requisite in Eq. (2), the present method is more convenient than other methods due to the fact that it is not easy to determine such ratios accurately, especially for complicated stiffening plate members in SCC BGs.

The FE analysis is conducted based on a standard harmonic response analysis, which has higher computational efficiency than the commonly used time-domain analysis. In the acoustic analysis, the calculation cost is very small. To sum up, the prediction method is very efficient for the estimation of the high-frequency vibration and associated structural noise of an SCC BG.

\subsection{Verification of numerical prediction}

To verify the accuracy of the aforementioned numerical simulation procedure, in situ measurements were conducted on the PC BG shown in Fig. 1b. Hereinafter, the measured vibro-acoustic responses of the $\mathrm{PC}$ BG are regarded as vibration and noise control objectives for the SCC BG shown in Fig. 1a. In other words, it is expected that the vibro-acoustic responses of the SCC BG can be as low as those of the PC BG. The PC BG had a span of $30 \mathrm{~m}$. An embedded-sleeper track was laid on the deck, and the rails were connected to the track slabs by railpads with a normal stiffness of $60 \mathrm{MN} / \mathrm{m}$. There were no vibration reduction measures between the track structure and the bridge. No other forms of vibration damping were used.

Figure 3 shows the arrangement of the measuring points. To capture the vibrations, three accelerometers (V1-V3) were fixed on the centers of the bottom plate, web, and flange, respectively. To capture the near-field noise, three microphones (S1-S3) were placed $0.3 \mathrm{~m}$ away from V1-V3, respectively. Microphone S4 was placed underneath the bridge girder, where the wheel/rail noise from above the bridge deck is largely shielded by the girder. To explore the far-field noise, microphone S5 was placed $25 \mathrm{~m}$ from the track centerline. Typical recordings of the vibration velocity and sound pressure in the time domain are shown in Fig. 4. For the PC bridge, the traininduced vibration and associated noise were much larger than the background ones, indicating the validity of the measured data.

The spectra of the measured VVL and SPL are shown in Fig. 5, where all the curves were processed according to A-weighted rules. Note that this treatment is aimed to find the spectral correlation between VVL and SPL. The VVL spectra have local peaks in the frequency bands of $63-125 \mathrm{~Hz}$ and $500-630 \mathrm{~Hz}$ (see Fig. 5a), which is consistent with the SPL spectra (see Fig. 5b). This suggests that the bridge-borne noise is mainly due to structural vibration, with little noise coming from other sources near the girder plates (e.g., wheel/rail noise). The VVL at V1 is the largest $(116.0 \mathrm{~dB}(\mathrm{~A}))$ followed by that at $\mathrm{V} 3$ (109.7 $\mathrm{dB}(\mathrm{A}))$, with that at V2 the smallest $(106.4 \mathrm{~dB}(\mathrm{~A}))$. However, the measured SPLs corresponding to the three
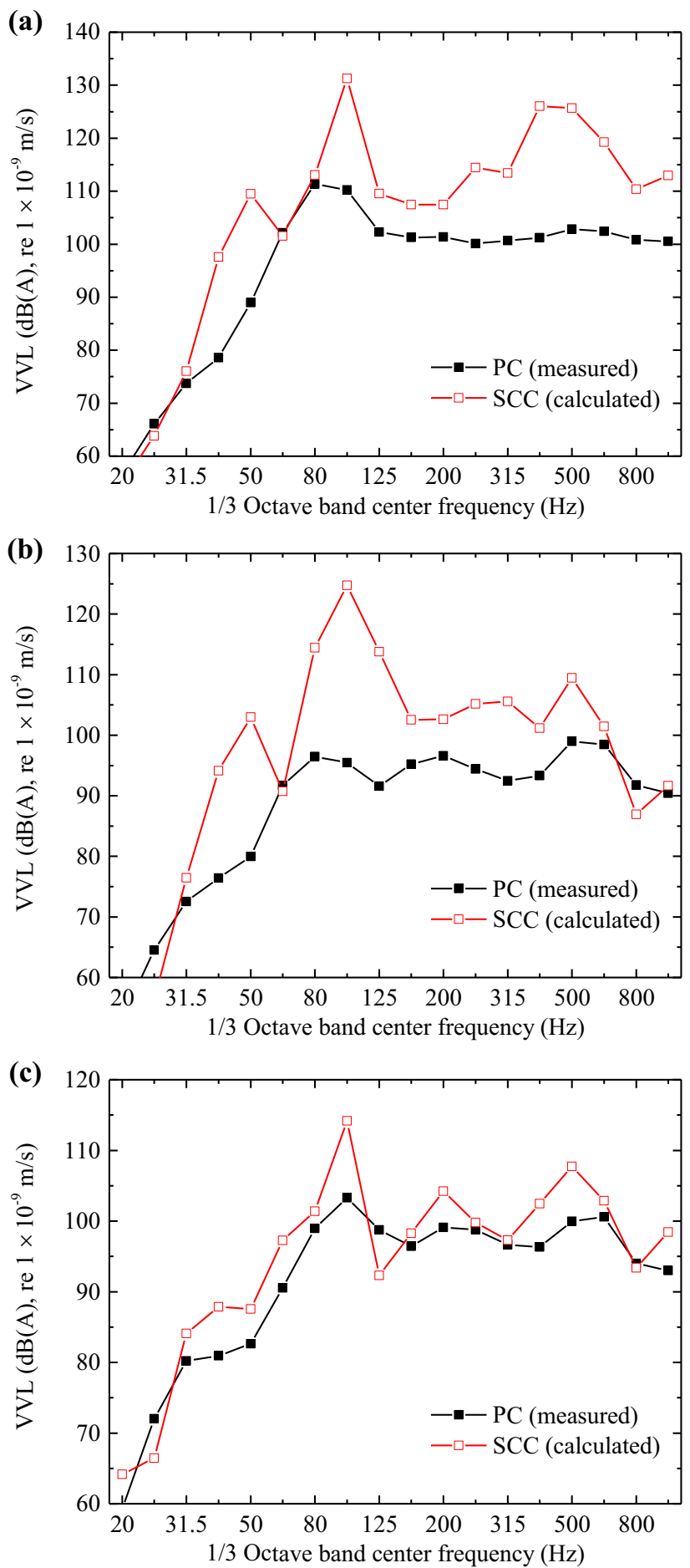

Fig. 11 Vibration comparison of SCC and PC BGs: a V1, b V2, and c V3 

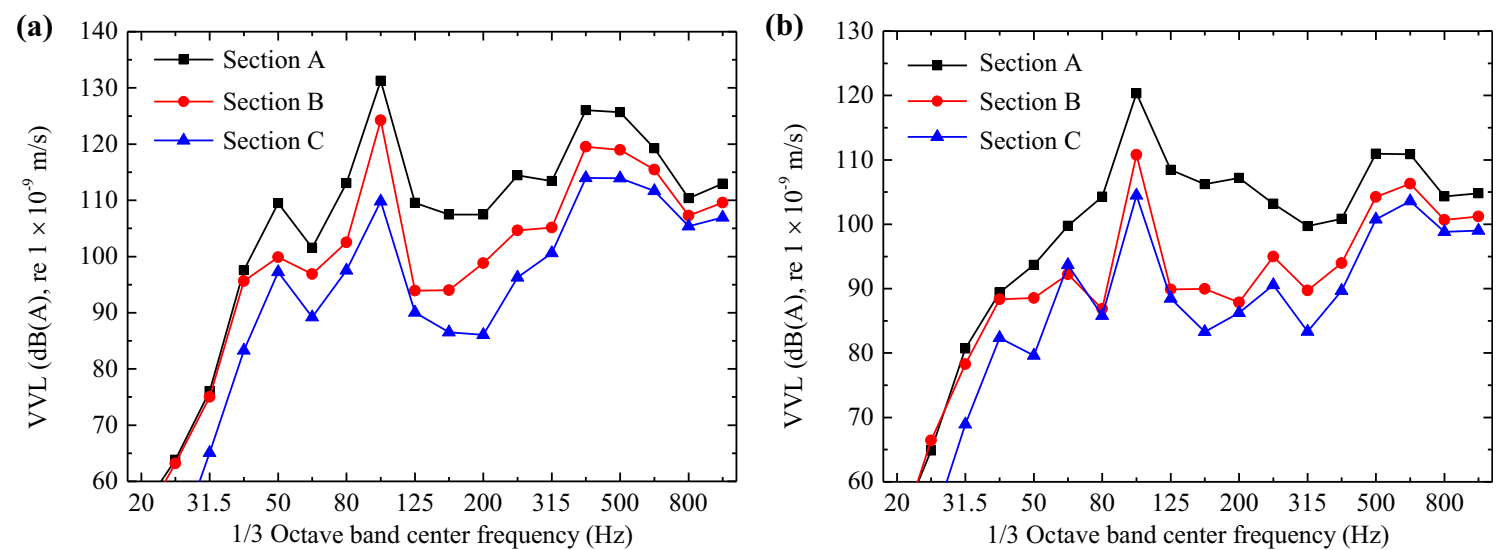

Fig. 12 Calculated vibration distributions for SCC BG: a bottom plate and b deck

locations exhibit some differences. For example, the SPLs at $\mathrm{S} 2$ and $\mathrm{S} 3$ are basically the same; this is because S2 and S3 are close together, and the noise radiated by the web and flange propagates freely between the two locations because there are no shielding obstacles between them. The overall SPLs at S1-S3 are 83.9, 81.4, and 82.2 dB(A), respectively. The S5 signal comprises bridge-borne noise and wheel/rail noise, while the bridge-borne noise at $\mathrm{S} 4$ predominates because the low-frequency component is much higher than the mid- and high-frequency components. The overall SPLs at S4 and S5 are 81.1 and $74.2 \mathrm{~dB}(\mathrm{~A})$, respectively.

In the numerical simulation, to predict the wheel/rail force accurately in the frequency range of $20-1000 \mathrm{~Hz}$, the power spectral density corresponding to typical shortwavelength roughness of $0.01-1 \mathrm{~m}$ is introduced, as shown in Fig. 6 [31]. The FE analysis was performed using the ANSYS software by applying harmonic forces transmitted to the bridge deck. The detailed train and track parameters are listed in Table 1.

Figure $7 \mathrm{a}-\mathrm{c}$ shows that the calculated values remain stable within $\pm 4 \mathrm{~dB}$ compared with the measured data (represented by mean and standard deviation) at locations V1, S1, and S4. Although obvious discrepancies between the measured and calculated results are observed at certain frequencies, their overall agreement is relatively good. The differences between the calculated and measured results at some frequencies may be due to uncertainties in the testing procedure and/or modeling errors. Given that the actual track roughness on the experimental bridge was not measured because of in-service control, the recommended roughness [31] was adjusted via nonlinear least-squares estimation to guarantee the closest matches between the measured and calculated results (herein, it refers to the vibration (V1-V3) and near-field noise (S1-S3)). Also, because the wheel/rail noise is not considered in the numerical simulation procedure, the calculated noise at location S4 (underneath the girder) is marginally smaller than the measured noise. At location S5 where the wheel/ rail noise predominates (see Fig. 7d), the mid- and highfrequency components of the calculated noise are much lower than the measured data. These results confirm that the numerical simulation procedure is accurate for vibroacoustic analysis. Also, because this numerical simulation procedure has nothing to do with structural material differences, it is equally applicable to SCC BGs.

\section{Vibro-acoustic analysis of SCC box girder}

\subsection{FE model}

The numerical method verified in Sect. 2 is used to predict the vibration and noise of the SCC BG shown in Fig. 1a, which has a span of $40 \mathrm{~m}$ and comprises four I-shaped steel girders, two steel bottom plates, and a concrete deck. The steel girders and concrete deck are connected by shear studs. Detailed dimensions are plotted in Fig. 1a. Diaphragms spaced at $4.5 \mathrm{~m}$ are used to increase the torsional rigidity of the $\mathrm{BG}$, and vertical stiffeners (1.5 m space) and one horizontal stiffener are used to improve the stability of the webs. The longitudinal stiffeners of the bottom plate enhance its bearing capacity.

Figure 8 shows the FE model. The steel girder is modeled by SHELL63 elements and the concrete deck by SOLID45 elements. The connection between the steel girder and concrete deck is assumed to have no slide, i.e., they are perfectly connected. In the FE model, the maximum element size is $0.1 \mathrm{~m}$, which agrees with the requirement of $1 / 4$ of the maximum wavelength [27]. How the structural parameters of the diaphragms, web stiffeners, and bottom plate stiffeners affect the vibro-acoustic responses of the SCC BG is discussed in Sect. 4.2. 

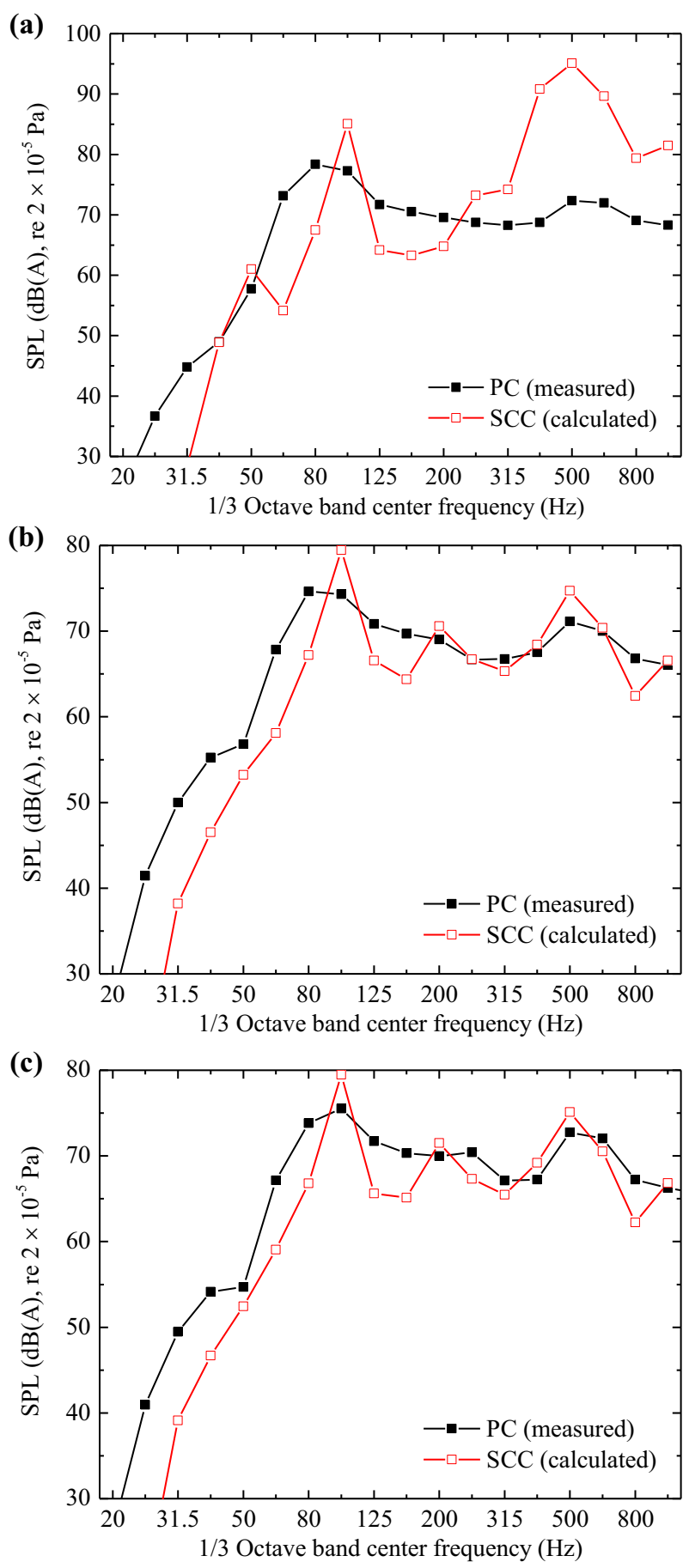

Fig. 13 Near-field noise comparison for SCC and PC BGs: a S1, b $\mathrm{S} 2$, and c $\mathrm{S} 3$

\subsection{Force transmission characteristics}

The calculated receptances of the track and BG are shown in Fig. 9a. In the considered frequency range $(20-1000 \mathrm{~Hz})$, the receptance of the SCC BG is marginally larger than that of the PC BG, but both are approximately one order of magnitude smaller than that of the track.
Therefore, both the SCC and PC BG can be regarded as a rigid foundation when calculating the track receptance, as assumed in Sect. 2.1.

In Fig. 9a, a peak occurs in the track receptance around $199 \mathrm{~Hz}$, coinciding with the natural frequency of the rail mass on the stiff railpad system. Above $300 \mathrm{~Hz}$, the track receptance fluctuates greatly because of the influence of multi-wheel interaction. To elaborate the characteristics of the coupled train-track model, the receptances of the wheel, contact spring, track, and their sum are shown in Fig. 9b. The total receptance has a minimum at around $70 \mathrm{~Hz}$, which is attributed to the natural frequency of the unsprung wheel mass oscillating on the stiff track. At this frequency, the receptance amplitudes of the wheel and track are roughly equal, but their phases are opposite, which leads to a local minimum of the total receptance. Overall, the total receptance is determined mainly by the wheel receptance in the frequency range of $20-40 \mathrm{~Hz}$ and is predominated mainly by the wheel and track receptances for $40-100 \mathrm{~Hz}$. Above $100 \mathrm{~Hz}$, the receptance sum is determined mainly by the track receptance.

Figure 10a shows the computed wheel-rail interaction force considering the influence of different track parameters, where "Railpad of normal stiffness" and "Railpad of low stiffness" correspond to a normal slab track, and for "Floating slab track" the railpad stiffness is that of the normal slab track. These track parameters are listed in Table 1. As can be seen, the wheel-rail contact force for the railpad of normal stiffness is similar to that of the floating slab track for $20-1000 \mathrm{~Hz}$. Beyond $600 \mathrm{~Hz}$, the wheel-rail interaction forces of the three tracks are basically equivalent. The maximum wheel-rail interaction force for the railpad of normal stiffness occurs at approximately $70 \mathrm{~Hz}$ because of the minimum receptance at this frequency. For $40-175 \mathrm{~Hz}$, the interaction force for the railpad of low stiffness is the smallest because the total receptance is the largest. Therefore, we conclude that the receptance is the critical factor for the variation of the wheel-rail interaction force.

As shown in Fig. 10b, the floating slab track corresponds to the smallest force transmitted to the bridge, followed by the railpad of low stiffness and then the railpad of normal stiffness. This demonstrates that the floating slab track is the most effective means of controlling the excitation applied to the bridge.

\subsection{Bridge vibration}

To control the vibro-acoustic level of the SCC BG to that of the PC BG, the calculated vibrations of the SCC BG are compared with the measured results for the $\mathrm{PC} \mathrm{BG}$, as shown in Fig. 11 for V1-V3. Because the first three peaks in the force transmitted to the bridge occur in the frequency 
(a)

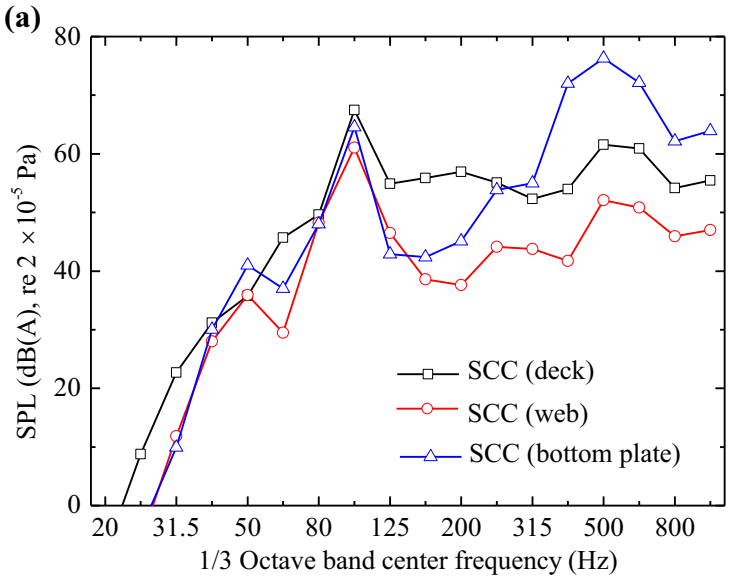

(b)

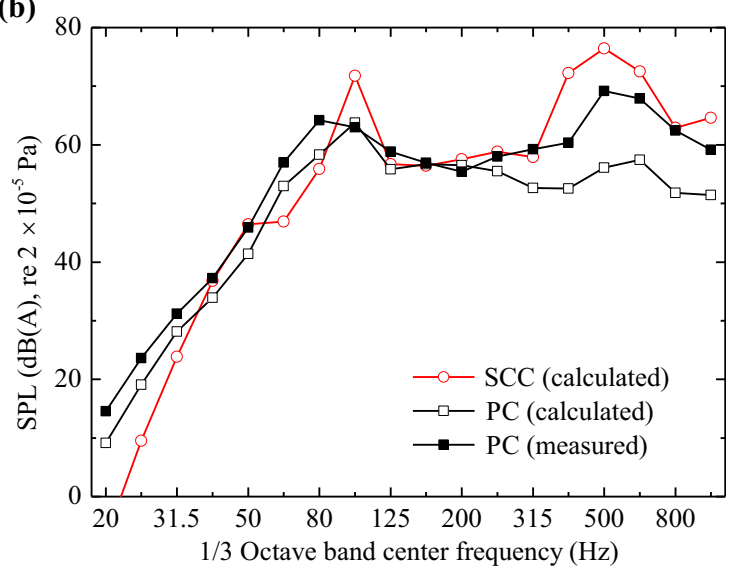

Fig. 14 Calculated noise contribution of SCC BG at location S5: a three main members and $\mathbf{b}$ their sum

ranges of $40-100 \mathrm{~Hz}, 200-400 \mathrm{~Hz}$, and $400-600 \mathrm{~Hz}$, respectively, the VVLs of the bottom plate, web, and flange of the SCC BG exhibit local peaks in these three frequency bands. However, there is another peak in the range of $31.5-50 \mathrm{~Hz}$, which may be due to local vibration of relevant structural members. Therefore, we conclude that the spectral characteristics of the force transmitted to the bridge and the natural vibration characteristics of the structural members are the two main factors that determine the frequency characteristics and amplitudes of bridge VVLs. For the SCC BG, the overall VVLs at V1-V3 are 133.7, 125.7, and $116.4 \mathrm{~dB}(\mathrm{~A})$, respectively. In comparison, the PC BG has lower vibration responses, with a maximum difference of $19.3 \mathrm{~dB}(\mathrm{~A})$ at the web and a minimum difference of $6.7 \mathrm{~dB}(\mathrm{~A})$ at the flange. This appears to come from the significant differences in material properties and plate thicknesses for the bottom plate and web.

To understand further the rules governing the distribution of vibration in the SCC BG, the VVLs of the bottom plate and deck at different cross-section locations are computed as shown in Fig. 12, where we compare the mid-, 1/4-, and 1/8-span cross sections (denoted by sections A-C, respectively, see Fig. 8). Figure 12 shows that the vibrations of the bottom plate and deck at sections $\mathrm{A}-\mathrm{C}$ depend similarly on frequency, indicating that the vibration in each plate of the SCC BG propagates gradually in the whole structure and decreases with distance in the span direction. The overall VVLs of the bottom plate and deck are 133.7 and $122.1 \mathrm{~dB}(\mathrm{~A})$, respectively, at section $\mathrm{A}$, 126.9 and $113.6 \mathrm{~dB}(\mathrm{~A})$, respectively, at section $\mathrm{B}$, and 119.3 and $109.3 \mathrm{~dB}(\mathrm{~A})$, respectively, at section C. Below $50 \mathrm{~Hz}$, these vibration curves are close to each other, suggesting that the vibration decay rate along the SCC BG is small at low frequency.

\subsection{Bridge-borne noise}

Figure 13a-c compares the near-field noise of the SCC and PC BGs at S1-S3. As can be seen, the SPL spectra for the SCC BG contain three peaks, and these frequency bands also match those in the spectra of the force transmitted to the bridge. Compared with the measured SPLs of the PC BG, the near-field noise emitted by the SCC BG is generally smaller at frequencies below $200 \mathrm{~Hz}$, except at certain peaks. Above $200 \mathrm{~Hz}$, the SCC BG radiates more noise at $\mathrm{S} 1$ than the PC BG, whereas the SPLs of the two BGs at S2 and S3 are close to each other. The overall SPL in the near field at $\mathrm{S} 1(97.8 \mathrm{~dB}(\mathrm{~A}))$ is the largest, followed by those at $\mathrm{S} 3(82.6 \mathrm{~dB}(\mathrm{~A}))$ and $\mathrm{S} 2(82.4 \mathrm{~dB}(\mathrm{~A}))$.

The noise contribution of the SCC BG at S5 is shown in Fig. 14a. The overall SPLs resulted from the bottom plate, deck, and web are 79.2, 70.4, and $62.7 \mathrm{~dB}(\mathrm{~A})$, respectively. While the noise from the three members does not differ significantly below $125 \mathrm{~Hz}$, the bottom plate and deck dominate the noise emanating from the bridge in the highfrequency range. Accordingly, the bottom plate and deck should be prioritized for noise reduction.

Figure 14b compares the SPLs at S5 for the SCC and PC BGs. There are no significant differences for $20-200 \mathrm{~Hz}$, whereas above $200 \mathrm{~Hz}$ the SCC-BG noise is much greater than the PC-BG one. The SCC-BG radiated noise $(80.1 \mathrm{~dB}(\mathrm{~A}))$ is $12.2 \mathrm{~dB}(\mathrm{~A})$ higher than the calculated result, and is $5.9 \mathrm{~dB}(\mathrm{~A})$ higher than the measured result for the PC BG. Therefore, even though the wheel/rail noise is not considered in the calculation, the bridge-borne noise of the SCC BG is higher than that of the PC in the middle frequency range $(400-630 \mathrm{~Hz})$. 

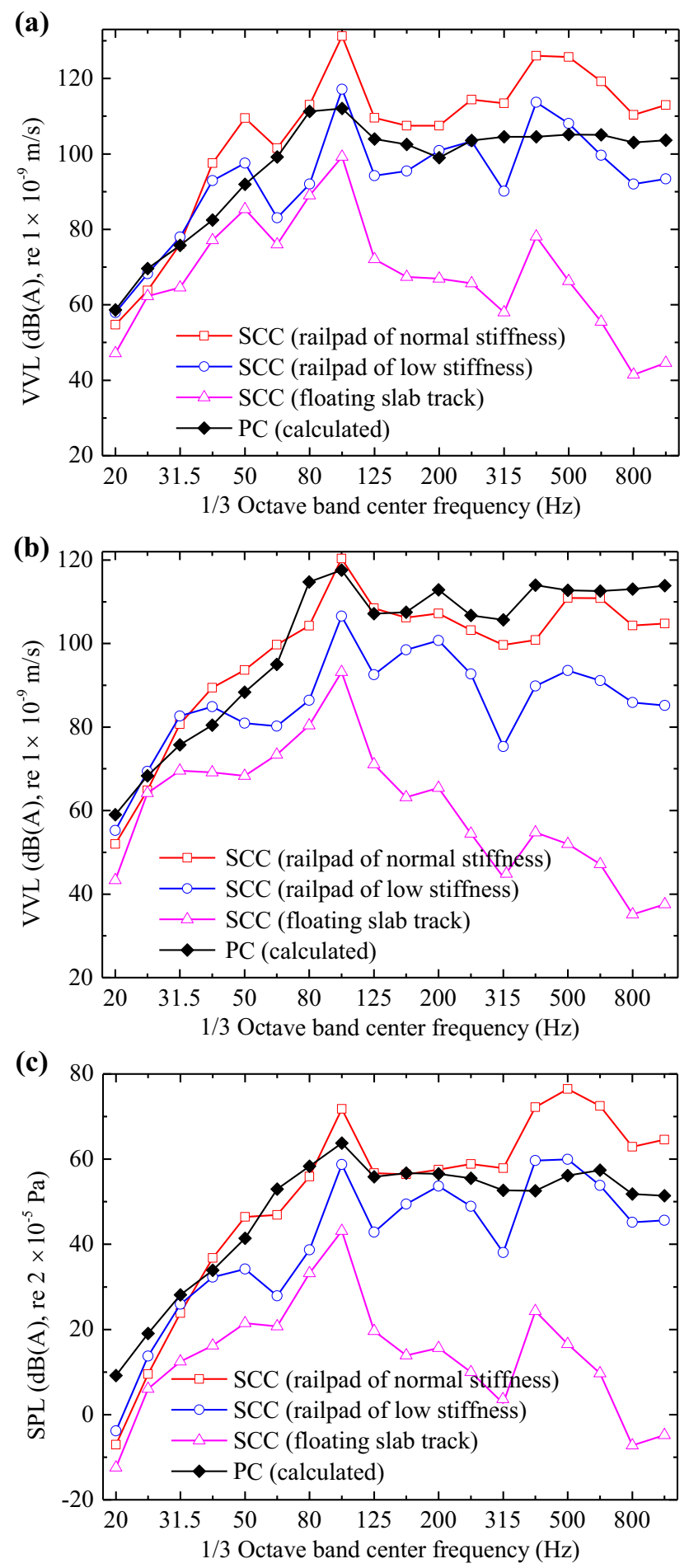

Fig. 15 Variation of vibration and noise using different track structures: a bottom-plate vibration, $\mathbf{b}$ deck vibration, and $\mathbf{c}$ noise at location S5

\section{Vibro-acoustic control measures}

\subsection{Track isolation}

Figure 15 presents the results of calculations of the VVL and SPL in the SCC BG using different track structures including the normal slab track with the railpads of normal and low stiffness and the floating slab track.

The frequencies corresponding to the peaks in the VVL and SPL spectra are close to those in the force spectra shown in Fig. 10b. This also verifies the conclusion in Sect. 3.3 that the frequency spectral characteristics of the force transmitted to the bridge determine the frequency bands of the VVL peaks. In addition, the relative VVL magnitude relationship of the three types of track structure and the force transmitted to the bridge are consistent regardless of the bottom plate or deck. The VVL in the SCC BG with the railpad of normal stiffness is the largest, where the VVLs of the bottom plate and deck are 133.7 and $122.1 \mathrm{~dB}(\mathrm{~A})$, respectively.

The above relationship also occurs in the SPL spectra at S5. The SPL of the SCC BG with the railpad of normal stiffness $(80.1 \mathrm{~dB}(\mathrm{~A}))$ is the largest, followed by those of the railpad of low stiffness $(65.3 \mathrm{~dB}(\mathrm{~A}))$ and the floating slab track $(43.7 \mathrm{~dB}(\mathrm{~A}))$. Although the high elastic railpad can largely reduce bridge vibration and structural noise, it may lead to abnormal rail corrugation and increased noise in the vehicle interior $[32,33]$. Therefore, we conclude that using the floating slab track and the track with the railpad of normal stiffness is a promising way to control the vibration and noise of the SCC BG, which can reduce the noise to the level comparable or even lower than those in the PC BG.

\subsection{Structural enhancement}

Here, we use numerical means to investigate how the structural parameters affect the vibration and noise reduction. The VVLs of the bottom plate and deck calculated with different structural parameters are shown in Fig. 16. We compare six structural enhancements: (i) changing the diaphragm spacing from 4.5 to $2.7 \mathrm{~m}$ (measure A), (ii) changing the spacing of the vertical stiffeners on the web from 1.5 to $0.9 \mathrm{~m}$ (measure $\mathrm{B} 1$ ), (iii) changing the spacing of the longitudinal stiffeners on the bottom plate from 0.5 to $0.25 \mathrm{~m}$ (measure $\mathrm{B} 2$ ), (iv) increasing the thickness of the web by $50 \%$ (measure $\mathrm{C} 1$ ), (v) increasing the thickness of the bottom plate by $50 \%$ (measure $\mathrm{C} 2$ ), and (vi) increasing the thickness of the deck by $50 \%$ (measure C3). These six measures are intended to increase the stiffness of some specific structural members.

Figures 16 and 17 show that with these measures, the peak frequencies in the VVL spectra remain basically 

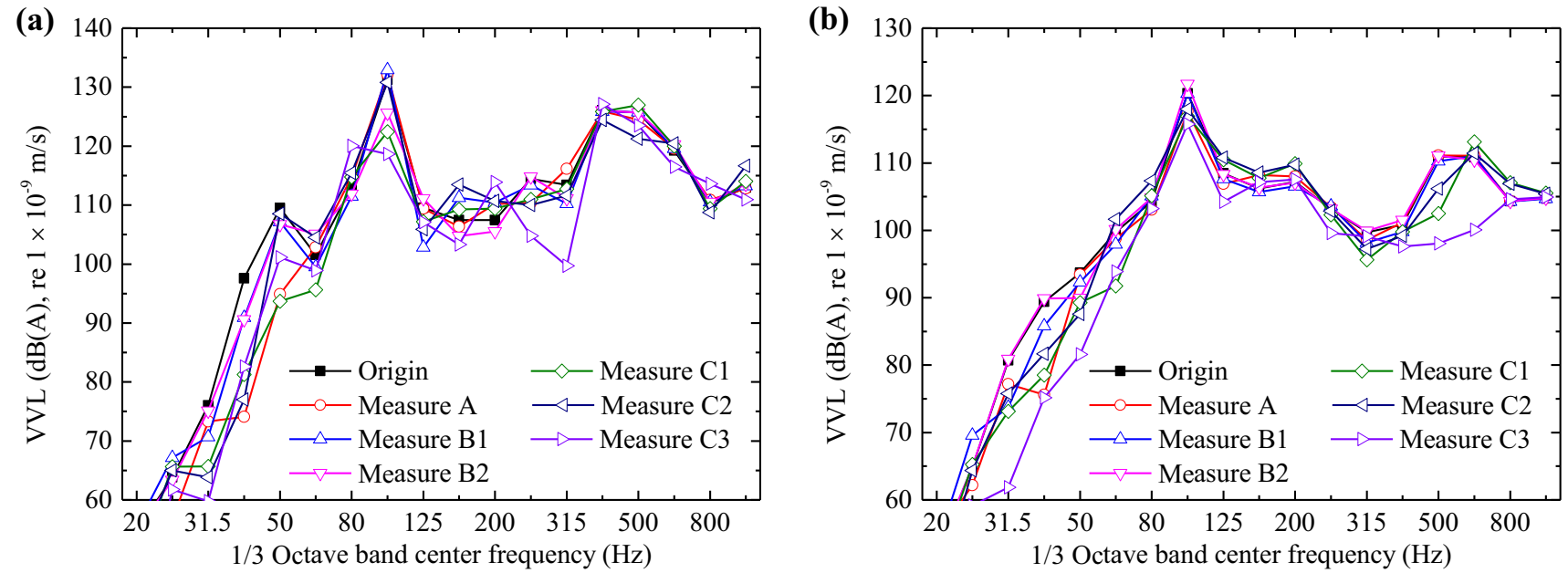

Fig. 16 Variation of bottom-plate and deck vibrations using different structural parameters: a bottom-plate vibration and $\mathbf{b}$ deck vibration

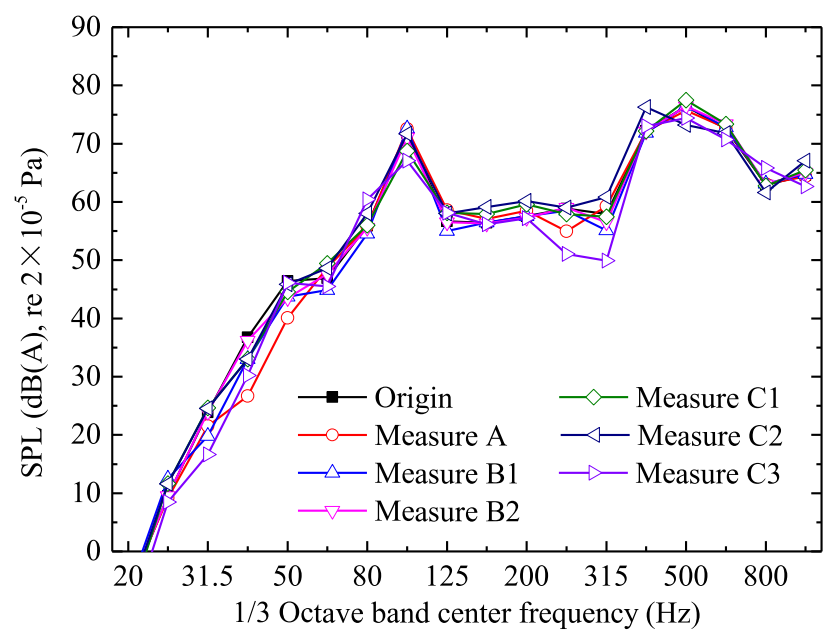

Fig. 17 Variation of noise at location S5 using different structural measures

unchanged around $100 \mathrm{~Hz}$, thereby indicating that these measures do not affect the peak frequency of the vibration. Additionally, the variation of the VVL spectra with frequency is similar with these measures, which reduce the bottom-plate vibration in the frequency range of $25-63 \mathrm{~Hz}$ and the deck vibration in the frequency ranges of $25-80 \mathrm{~Hz}$ and $400-800 \mathrm{~Hz}$. With each measure, the decrease in the overall VVL is within 1.1-3.6 dB(A).

The calculated SPLs at S5 using these measures are shown in Fig. 17. Compared to the vibration variation, the noise fluctuation is not noticeable. With these measures, the peak frequencies in the SPL spectra also are basically identical around $100 \mathrm{~Hz}$. These SPL curves are close to each other, showing that the noise reduction effect is not obvious. Of these measures, the maximum noise reduction of measure $\mathrm{C} 3$ is only $1.5 \mathrm{~dB}(\mathrm{~A})$.

\section{Conclusions}

In this study, a numerical predictive procedure was proposed for predicting bridge-borne noise and then validated by in situ measurements on a PC BG. Through vibroacoustic comparison between the PC and SCC BGs based on numerical simulation, the vibro-acoustic control for the SCC BG was discussed. The main conclusions of this study are summarized as follows:

(1) The vibration and noise of the PC BG model in frequency domain agreed well with the measured data. The proposed method was shown to be technically feasible and could predict the vibration and noise of the SCC BG with acceptable accuracy.

(2) The vibration response of the SCC box girder is larger than that of the $\mathrm{PC}$ box girder with a maximum difference of about $19.3 \mathrm{~dB}(\mathrm{~A})$ at the web and a minimum difference of about $6.7 \mathrm{~dB}(\mathrm{~A})$ at the flange in total VVL. In the far field, the noise from the SCC BG was 12.2 and $5.9 \mathrm{~dB}(\mathrm{~A})$ larger than that calculated and measured for the PC BG, respectively.

(3) Track isolation may be the best choice for vibroacoustic control on the SCC BG, because the force transmitted to the bridge plays a major role in vibroacoustic response. Using a floating slab track reduced the vibration and noise of the SCC BG, which was lower than those for the PC BG. By contrast, the effects of structural enhancement on vibration and noise reduction were very limited in reducing the vibration by $1.1-3.6 \mathrm{~dB}(\mathrm{~A})$ and the noise by up to $1.5 \mathrm{~dB}(\mathrm{~A})$. 
Acknowledgements This study was supported by the National Natural Science Foundation of China (Nos. 51778534 and 51978580).

Open Access This article is licensed under a Creative Commons Attribution 4.0 International License, which permits use, sharing, adaptation, distribution and reproduction in any medium or format, as long as you give appropriate credit to the original author(s) and the source, provide a link to the Creative Commons licence, and indicate if changes were made. The images or other third party material in this article are included in the article's Creative Commons licence, unless indicated otherwise in a credit line to the material. If material is not included in the article's Creative Commons licence and your intended use is not permitted by statutory regulation or exceeds the permitted use, you will need to obtain permission directly from the copyright holder. To view a copy of this licence, visit http://creativecommons.org/licenses/by/4.0/.

\section{References}

1. Gao QF, Zhang K, Wang T, Peng WK, Liu CQ (2021) Numerical investigation of the dynamic responses of steel-concrete girder bridges subjected to moving vehicular loads. Meas Control 54(3-4):465-484

2. Thompson DJ (2009) Railway noise and vibration: mechanisms, modeling and means of control. Elsevier, Oxford

3. Ghimire JP, Matsumoto Y, Yamaguchi H, Kurahashi I (2009) Numerical investigation of noise generation and radiation from an existing modular expansion joint between prestressed concrete bridges. J Sound Vib 328(1-2):129-147

4. Alten K, Flesch R (2012) Finite element simulation prior to reconstruction of a steel railway bridge to reduce structure-borne noise. Eng Struct 53(2):83-88

5. Lee YY, Ngai KW, Ng CF (2004) The local vibration modes due to impact on the edge of a viaduct. Appl Acoust 65(11):1077-1093

6. Li Q, Xu YL, Wu DJ (2012) Concrete bridge-borne low-frequency noise simulation based on train-track-bridge dynamic interaction. J Sound Vib 331(10):2457-2470

7. Zhang X, Li XZ, Hao H, Wang DX, Li YD (2016) A case study of interior low-frequency noise from box-shaped bridge girders induced by running trains: Its mechanism, prediction and countermeasures. J Sound Vib 367:129-144

8. Ngai KW, Ng CF (2002) Structure-borne noise and vibration of concrete box structure and rail viaduct. J Sound Vib 255(2):281-297

9. Li X, Zhang X, Zhang Z, Liu Q, Li Y (2013) Experimental research on noise emanating from concrete box-girder bridges on intercity railway lines. Pro Inst Mech Eng F-J Rail Rapid Transit 229(2):125-135

10. Li X, Yang D, Chen G, Li Y, Zhang X (2016) Review of recent progress in studies on noise emanating from rail transit bridges. J Mod Transport 24(4):237-250

11. Zhang X, Li X, Liu Q, Wu J, Li Y (2013) Theoretical and experimental investigation on bridge-borne noise under moving high-speed train. Sci China Technol Sc 56(4):917-924

12. Li Q, Song X, Wu D (2014) A 2.5-dimensional method for the prediction of structure-borne low-frequency noise from concrete rail transit bridges. J Acoust Soc Am 135(5):2718-2726

13. Song X, Wu D, Li Q, Botteldooren D (2016) Structure-borne lowfrequency noise from multi-span bridges: a prediction method and spatial distribution. J Sound Vib 367:114-128

14. Song X, Li Q, Wu DJ (2016) Investigation of rail noise and bridge noise using a combined 3D dynamic model and 2.5D acoustic model. Appl Acoust 109:5-17

15. Li Q, Thompson DJ (2018) Prediction of rail and bridge noise arising from concrete railway viaducts by using a multilayer rail fastener model and a wavenumber domain method. Pro Inst Mech Eng F-J Rail Rapid Transit 232(5):1326-1346

16. Song L, Li X, Zheng J, Guo M, Wang X (2020) Vibro-acoustic analysis of a rail transit continuous rigid frame box girder bridge based on a hybrid WFE-2D BE method. Appl Acoust 157:107028

17. Song L, Li X, Hao H, Zhang X (2018) Medium- and high-frequency vibration characteristics of a box-girder by the waveguide finite element method. Int J Struct Stab Dy 18(11):1850141

18. Zhong T, Chen G, Sheng X, Zhan X, Zhou LQ, Kai J (2018) Vibration and sound radiation of a rotating train wheel subject to a vertical harmonic wheel-rail force. J Mod Transport 26(2):81-95

19. Augusztinovicz F, M F, Guly K, Nagy AB, Fiala P, Gajd P, (2006) Derivation of train track isolation requirement for a steel road bridge based on vibro-acoustic analyses. J Sound Vib 293(3-5):953-964

20. Li X, Liu Q, Pei S, Song L, Zhang X (2015) Structure-borne noise of railway composite bridge: numerical simulation and experimental validation. J Sound Vib 353:378-394

21. Liu Q, Li X, Zhang X, Zhou Y, Chen Y (2020) Applying constrained layer damping to reduce vibration and noise from a steelconcrete composite bridge: an experimental and numerical investigation. J Sandw Struct Mater 22(6):1743-1769

22. Liang L, Li X, Yin J, Wang D, Gao W, Guo Z (2019) Vibration characteristics of damping pad floating slab on the long-span steel truss cable-stayed bridge in urban rail transit. Eng Struct 191:92-103

23. Liu Q, Thompson DJ, Xu P, Feng Q, Li X (2020) Investigation of train-induced vibration and noise from a steel-concrete composite railway bridge using a hybrid finite element-statistical energy analysis method. J Sound Vib 471:115197

24. Poisson F, Margiocchi F (2006) The use of dynamic dampers on the rail to reduce the noise of steel railway bridges. J Sound Vib 293(3-5):944-952

25. Zhang X, Liu R, Cao Z, Wang X, Li X (2019) Acoustic performance of a semi-closed noise barrier installed on a high-speed railway bridge: measurement and analysis considering actual service conditions. Measurement 138:386-399

26. Zhang X, Cao Z, Ruan L, Li X, Li X (2021) Reduction of vibration and noise in rail transit steel bridges using elastomer mats: numerical analysis and experimental validation. Pro Inst Mech Eng F-J Rail Rapid Transit 235(2):248-261

27. Zhang X, Li X, Wen Z, Zhao Y (2018) Numerical and experimental investigation into the mid- and high-frequency vibration behavior of a concrete box girder bridge induced by high-speed trains. J Vib Control 24(23):5597-5609

28. Xu L, Zhai W (2020) Train-track coupled dynamics analysis: system spatial variation on geometry, physics and mechanics. Rail Eng Science 28(1):36-53

29. Wu T, Thompson DJ (2002) Behaviour of the normal contact force under multiple wheel/rail interaction. Vehicle Syst Dyn 37(3):157-174

30. Fahy FJ, Gardonio P (2007) Sound and structural vibration: radiation, transmission and response, 2nd edn. Oxford University Press, Oxford

31. Zhai W, Wang K, Cai C (2009) Fundamentals of vehicle-track coupled dynamics. Vehicle Syst Dyn 47(11):1349-1376

32. Li L, Thompson DJ, Xie Y, Zhu Q, Luo Y, Lei Z (2019) Influence of rail fastener stiffness on railway vehicle interior noise. Appl Acoust 145:69-81

33. Xiao H, Yang S, Wang H, Wu S (2018) Initiation and development of rail corrugation based on track vibration in metro systems. Pro Inst Mech Eng F-J Rail Rapid Transit 232(9):2228-2243 